- Smoking, alcohol and drug use by vocational dental practitioners (VDPs) in 2005 is compared to use by VDPs in 2000.

- This paper allows trends in use of the substances surveyed to be monitored.

- The results of this study can be used to promote an evidence-based approach to the education of VDPs on the use of tobacco, alcohol and drugs.

- This paper is relevant to all areas of the profession, especially those responsible for the education of undergraduates and VDPs.

\title{
Smoking, alcohol and drug use among vocational dental practitioners in 2000 and 2005
}

\author{
B. Underwood, ${ }^{1}$ A. Hackshaw ${ }^{2}$ and K. Fox ${ }^{3}$
}

Objective To estimate the prevalence of tobacco smoking, alcohol and drug use among UK vocational dental practitioners (VDPs) in 2005, and compare these with prevalence in 2000.

Design Cross-sectional survey using an anonymous self-report questionnaire.

Subjects and methods All 767 VDPs who started practice in the summer of 2004 were sent a questionnaire in order to obtain data on the frequency and amount of tobacco, alcohol, cannabis and other illicit drugs used before and during vocational training (VT). The same survey had been conducted on VDPs five years earlier. The analysis was based on 502 subjects who responded and completed the questionnaire in 2005 and 534 subjects in 2000.

Results Regular tobacco use (10+ cigarettes per day) was reported by $5.4 \%$ of males and $4.0 \%$ of females in 2005 . This is lower than reported in 2000 (9\%) and a statistically significant reduction in males. Eighty-two percent of males and $81 \%$ of females reported alcohol use; a statistically significant reduction from 2000 (89\% males and 88\% females). Reported 'binge drinking' remained high with $44 \%$ of males and $39 \%$ of females drinking at least half the recommended weekly units of alcohol in one session, similar to those levels seen in 2000. Thirty-eight percent of males and $26 \%$ of females reported cannabis use during their VT, similar to levels seen in 2000. Reported use of illicit drugs other than cannabis was less than in 2000. Reported illicit drug use was associated with alcohol drinking, and particularly with tobacco use.

Conclusion This study has found the level of alcohol, tobacco and illicit drug use (excluding cannabis) among VDPs decreasing since 2000, but levels of binge drinking and cannabis use remaining similar.

${ }^{*}$ GDP/Researcher; ${ }^{2}$ Deputy Director/Senior Lecturer in Epidemiology, Cancer Research UK \& UCL Cancer Trials Centre, 90 Tottenham Court Road, London, W1T 4TJ; ${ }^{3}$ Lecturer in Restorative Dentistry, School of Dental Sciences, University of Liverpool, Pembroke Place, Liverpool, L3 5PS

${ }^{*}$ Correspondence to: Ben Underwood

Email: bfdunderwood@btopenworld.com

\section{Refereed Paper}

Accepted 24 April 2007

DOI: 10.1038/bdj.2007.1112

${ }^{\circledR}$ British Dental Journal 2007; 203: 701-705

\section{INTRODUCTION}

Vocational dental practitioners (VDPs) are newly qualified dental graduates, who must complete one year of vocational training (VT) before they can be allocated dental list numbers by a primary care trust enabling them to work as principals in the general dental services and personal dental services. ${ }^{1}$ The majority of graduates commence VT in July/August of the year they qualify.

A survey of cigarette smoking, alcohol and drug use carried out in 2000 on UK VDPs ${ }^{2}$ showed that their alcohol consumption was, on average, above sensible limits, and many were binge drinking, using tobacco and indulging in illicit drug use to a degree that will cause health problems later on in life. However, use of all substances had reduced since qualification.

The General Dental Council's (GDC) ethical guidance, Standards for dental professionals, ${ }^{3}$ replaced Maintaining standards ${ }^{4}$ in June 2005. Unlike Maintaining standards, Standards for dental professionals does not specifically comment on alcohol and drug use and misuse. However, the GDC does expect:

'...all registrants to maintain appropriate standards of personal behaviour. This would include the use and misuse of alcohol and drugs. In addition, the GDC would remind all registrants of their professional obligation to put patients' interests first and act to protect them.

'Problems with alcohol and/or drug dependency could lead to a dentist being referred through the GDCs Fitness to Practise procedures to the Health Committee. ${ }^{5}$

Cigarette smoking in the UK general population saw a steady downward trend from $1998 / 99$ to 2005 , decreasing from $28 \%$ of the population to $24 \% .{ }^{6}$ Thirty-two percent of adults aged 20 to 24 smoked in 2005, the highest level for any age group. The majority of VDPs fit into this age group.

Alcohol use among the general population has increased in the last 10 years. In England, the average weekly alcohol consumption in the last 12 months for men has increased from 15.7 units in 1992 to 17.0 units in $2002 .^{7}$ For women there was an increase from 5.5 to 7.6 units during the same period. In 2002 in England, 27\% of men drank more than the recommended weekly limit of 21 units. This proportion has remained 
largely unchanged since 1992. Among women, however, the proportion drinking more than the recommended weekly limit of 14 units, increased from 12\% in 1992 to $17 \%$ in $2002 .^{7}$ Fortunately, this upward trend in heavy drinking among young women appears to have peaked, with a recent study reporting $28 \%$ of 16-24 year old women had drunk more than six units on at least one day in the previous week in 2002, reducing to $22 \%$ in $2005 .^{8}$

Studies looking at trends in illicit drug use among 'young people' (people under the age of 25) in the general population" ${ }^{11}$ give a far from clear picture. It appears from the evidence currently available that the number of 'young people' in Britain using illicit drugs is stabilising, with the majority of longitudinal studies reporting a slight fall since 1995. There is a belief that 'recreational drug use is in the process of becoming normalised among British youth'. ${ }^{12}$

It is not known if trends in tobacco smoking, alcohol and illicit drug use seen in the general population have occurred among VDPs.

The aim of this study was to survey all UK VDPs in 2005 in order to ascertain their smoking, drug and alcohol use during and prior to VT. It will also show how reported smoking, alcohol and drug use has changed since 2000 to help identify trends in use among VDPs. This will increase understanding of an area which is of significance to all branches of the profession, especially those responsible for the undergraduate and VT curriculum. It is the authors' intention to repeat this survey every five years to monitor future trends in smoking, alcohol and drug use among VDPs.

\section{METHOD}

A cross-sectional survey was conducted of all VDPs in the UK $(n=767)$ who started in the summer of 2004. It was a repeat of a survey carried out by the lead author five years earlier. Packs containing self-report questionnaires were sent by recorded delivery to all UK VDP advisors $(\mathrm{n}=77)$, for distribution to their VDP groups at their next study day.

The questionnaire (copies available from the corresponding author) requested information on the frequency and amount of tobacco smoking, alcohol and eight specific illicit drugs. Questions were asked in a closed-ended format in Standard English. The questionnaire had been successfully piloted in 2000. Completion of the questionnaire usually took no longer than five minutes. Participants were provided with a free pen to act as an incentive to respond.

Once completed, participants were instructed to seal their questionnaire in a self-seal tamper-proof envelope. The envelopes from the entire group were then placed in a large tamperproof pre-paid return envelope, to be posted to the organisers. VDP advisors were requested to seal these envelopes in front of the group, reinforcing the desire for complete confidentiality.

The questionnaire was distributed to VDPs in January 2005, the same month as the 2000 questionnaire. Anonymity of participants was essential and therefore no name, age or ethnic group was requested. It was stressed that completion of the questionnaire was voluntary with no obligation to respond.

\section{Ethical approval}

Due to the design of the questionnaire, with VDPs not being asked to report their age or ethnic origin, ethical approval was
Table 1 Tobacco smoking reported by VDPs in 2000 and 2005

\begin{tabular}{|l|l|l|l|l|}
\hline & \multicolumn{2}{|c|}{ Males } & \multicolumn{2}{c|}{ Females } \\
\hline & $\begin{array}{l}\text { Smoking* } \\
\%(n)\end{array}$ & $\begin{array}{l}\geq 10 \text { cigarettes/ } \\
\text { day \% (n) }\end{array}$ & $\begin{array}{l}\text { Smoking } \\
\%(n)\end{array}$ & $\begin{array}{l}\geq 10 \text { cigarettes/ } \\
\text { day \% (n) }\end{array}$ \\
\hline 2000 & $33.0(89 / 270)$ & $12.6(34 / 270)$ & $21.2(56 / 264)$ & $5.7(15 / 264)$ \\
\hline 2005 & $20.5(46 / 224)$ & $5.4(12 / 224)$ & $16.2(45 / 278)$ & $4.0(11 / 278)$ \\
\hline Difference & 12.5 & 7.2 & 5.0 & 1.7 \\
\hline$p$ value & 0.002 & 0.004 & 0.13 & 0.35 \\
\hline
\end{tabular}

*Defined as those who reported smoking tobacco only whilst drinking alcohol or taking cannabis or regularly smoking $10+$ cigarettes per day.

Table 2 Level of alcohol consumption and knowledge of safe drinking
limits reported by VDPs who consume alcohol in 2000 and 2005

Alcohol consumption last week

\begin{tabular}{l|l|l|l|l}
\hline Sensible & 57.0 & 47.8 & 56.4 & 65.1 \\
\hline Increased & 25.6 & 27.2 & 28.4 & 13.7 \\
\hline Hazardous & 5.2 & 6.7 & 1.9 & 1.8 \\
\hline
\end{tabular}

Alcohol consumption during an average week

\begin{tabular}{|l|l|l|l|l|}
\hline Sensible & 62.2 & 55.8 & 64.4 & 66.6 \\
\hline Increased & 25.2 & 24.1 & 20.1 & 11.5 \\
\hline Hazardous & 0.7 & 1.3 & 0.4 & 1.1 \\
\hline
\end{tabular}

Alcohol consumption during an average drinking session

\begin{tabular}{|l|l|l|l|l|}
\hline $1-6$ units & 22.6 & 20.1 & 42.2 & 41.0 \\
\hline $7-9$ units & 23.7 & 17.9 & 28.5 & 26.6 \\
\hline$\geq 10$ units & 42.6 & 44.2 & 16.4 & 12.6 \\
\hline
\end{tabular}

Estimate of safe weekly maximum

\begin{tabular}{|l|l|l|l|l|}
\hline $0-7$ units & 8.5 & 12.5 & 22.0 & 26.6 \\
\hline 14 units & 12.6 & 16.1 & 42.4 & 40.6 \\
\hline 21 units & 33.7 & 33.0 & 20.4 & 10.8 \\
\hline 28 units & 28.2 & 16.1 & 1.5 & 1.4 \\
\hline$\geq 35$ units & 6.3 & 4.9 & 0.8 & 0.4 \\
\hline
\end{tabular}

The percentages are expressed as a proportion of all VDPs, so they do not sum to $100 \%$ (the remainder is associated with non-drinkers and a few drinkers who did not report their alcohol consumption).

Sensible level of alcohol consumption/week $=0-21$ units males, 0-14 females

Increased risk level of alcohol consumption/week $=22-49$ units males, 15-35 females.

Hazardous to health level of alcohol consumption/week $=50+$ units males, $36+$ females.

Safe weekly maximum $=21$ units for males and 14 units for females.

not required. However, approval for the survey was given by Mr Russ Ladwa, Chairman, Dental Vocational Training Authority for England and Wales (2004-6).

\section{Statistical analysis}

Statistical analysis was carried out using Statistical Analysis System (SAS). Results are mainly descriptive. The chi-squared test was used to make comparisons between 2000 and 2005. 


\section{RESULTS}

Fifty-one packs of the 77 sent were returned, containing 522 completed questionnaires (of a possible 767 if all packs had been returned) giving a response rate of $68 \%$. Due to the anonymous method it was impossible to investigate why some VDP advisors did not distribute or return their group's packs. Of the 522 questionnaires returned, 20 people failed to complete the questionnaire. The following analyses were therefore based on 502 respondents, giving a 66\% usable response rate of which 224 (45\%) were male and 278 (55\%) were female. The survey in 2000 was based on 534 respondents who completed the questionnaire at the time.

\section{Tobacco smoking}

The prevalence of tobacco smoking, when defined as those who smoke only whilst drinking alcohol or taking cannabis or those who smoke $\geq 10$ cigarettes per day, was $20.5 \%$ and $16.2 \%$ in males and females respectively. The proportion of VDPs who regularly smoked $\geq 10$ cigarettes per day was $5.4 \%$ and $4.0 \%$ in males and females respectively. The estimates of smoking prevalence are lower than those seen in the 2000 survey (Table 1). Noticeably, the reductions were larger among males and statistically significant ( $p$ values are $\leq 0.004$ ). The reductions in females were not statistically significant ( $p$ values are $\geq 0.13$ ).

\section{Alcohol}

The prevalence of alcohol drinking at any time during VT was $82 \%$ and $81 \%$ among male and females respectively; statistically significantly lower than the estimates in 2000: 89\% ( $p=$ $0.018)$ and $88 \%(p=0.025)$ for males and females respectively. However, a high proportion of VDPs still reported drinking above recommended levels. Figure 1 shows the percentage of all VDPs whose consumption the previous week was greater than the recommended levels. Whilst drinking above sensible limits is as common in males in 2005 as it was in 2000, the proportion of females who consumed more than the recommended level halved (30\% in 2000 and 15\% in 2005; p <0.001).
Binge drinking ${ }^{13}$ (defined as drinking at least half the recommended weekly limit of alcohol in one session, ie at least seven units for women and ten units for men in this study) remains high, with $44 \%$ of all male VDPs drinking $\geq 10$ units in an average drinking session, and 39\% of females drinking $\geq 7$ units.

Table 2 shows the detailed results on alcohol intake according to gender. The VDPs were asked to estimate what they thought was the safe weekly maximum of alcohol intake per week. Twenty-one percent of male respondents thought that their safe weekly maximum consumption is at least 28 units per week, while 13\% of females believed their weekly limit is at least 21 units. The recommended limits are lower - 21 and 14 units for males and females respectively - indicating that some VDPs do not know what the limits are. Nevertheless, the proportions who overestimated the recommended safe limit are much lower than in 2000; 35\% of males and 23\% of females.

Whether a VDP drank or not remained largely the same before becoming a VDP and during their VT year. Only a small proportion of those who drank alcohol before becoming a VDP

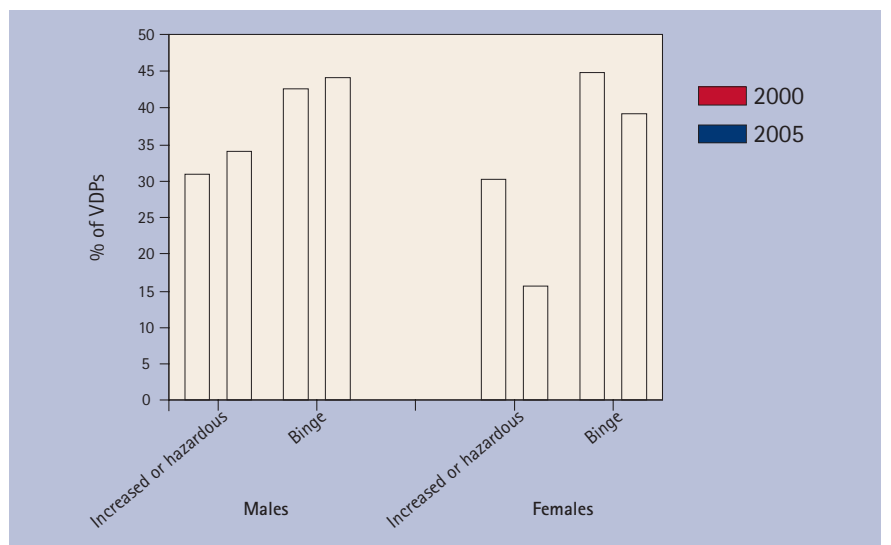

Fig. 1 Reported alcohol consumption during the previous week by VDPs in 2000 and 2005. 'Increased risk' level is 22-49 and 15-25 units for males and females respectively; 'hazardous' level is $\geq 50$ and $\geq 36$ units for males and females respectively. Binge drinking is defined as consuming $\geq 7$ units and $\geq 10$ units in one session for males and females respectively

Table 3 Reported illicit drug use (including amyl nitrate and inhalants which are not classified as illegal to use) whilst a VDP in 2000 and 2005

\begin{tabular}{|c|c|c|c|c|c|c|c|c|}
\hline & \multicolumn{4}{|l|}{ Males } & \multicolumn{4}{|l|}{ Females } \\
\hline & \multicolumn{2}{|c|}{$2000(n=270)$} & \multicolumn{2}{|c|}{$2005(n=224)$} & \multicolumn{2}{|c|}{$2000(n=264)$} & \multicolumn{2}{|c|}{$2005(n=278)$} \\
\hline & $\begin{array}{l}\text { Ever user } \\
(\%)\end{array}$ & $\begin{array}{l}\text { Current user } \\
(\%)\end{array}$ & $\begin{array}{l}\text { Ever user } \\
(\%)\end{array}$ & $\begin{array}{l}\text { Current user } \\
(\%)\end{array}$ & $\begin{array}{l}\text { Ever user } \\
(\%)\end{array}$ & $\begin{array}{l}\text { Current user } \\
(\%)\end{array}$ & $\begin{array}{l}\text { Ever user } \\
(\%)\end{array}$ & $\begin{array}{l}\text { Current user } \\
(\%)\end{array}$ \\
\hline Cannabis & 34.4 & 20.0 & 38.0 & 17.0 & 31.8 & 15.2 & 25.5 & 12.2 \\
\hline Amphetamines & 11.8 & 4.8 & 4.0 & 2.2 & 5.3 & 0.8 & 2.2 & 0.7 \\
\hline LSD & 9.6 & 1.8 & 2.7 & 0.9 & 0.8 & 0.4 & 0.4 & 0 \\
\hline Ecstasy & 10.7 & 4.1 & 6.7 & 4.0 & 5.7 & 2.6 & 2.5 & 0.7 \\
\hline Cocaine & 11.1 & 4.4 & 8.5 & 2.7 & 5.7 & 3.8 & 2.2 & 1.4 \\
\hline Amyl nitrate & 10.7 & 1.8 & 4.9 & 1.3 & 3.0 & 0.8 & 2.9 & 0.7 \\
\hline Inhalants & 2.2 & 0 & 1.3 & 0 & 0.4 & 0.4 & 0.4 & 0.4 \\
\hline Magic mushroom & 7.4 & 1.5 & 6.2 & 1.3 & 3.8 & 0.4 & 1.4 & 0 \\
\hline Any drug use & 35.9 & 22.2 & 38.8 & 17.9 & 32.2 & 15.9 & 27.0 & 12.6 \\
\hline
\end{tabular}


reported stopping during their VT year; 5\% (9/192) of males and $2 \%(5 / 229)$ of females.

\section{Cannabis}

Of all VDPs, 38\% of males and 26\% of females reported cannabis use during their VT; $17 \%$ and $12 \%$ of males and females respectively used it more than once/twice or at least once a week. Before becoming a VDP, 52\% of all males and 43\% of all females had used cannabis. Levels were generally lower in 2005 than they were in 2000 (Table 3), but the differences were not statistically significant.

Some VDPs reported that they used cannabis for the first time during their VT year; 6\% (6/104) of males who had never tried it before, did so at least once or twice; the estimate for females was $4 \%(6 / 165)$. However, a large proportion of those who used cannabis before becoming a VDP quit completely during their VT year; 32\% (38/117) males and 43\% (48/112) females.

\section{Other illicit drugs, amyl nitrate and inhalant use}

The reported use of illicit drugs (including amyl nitrate ${ }^{14}$ and inhalants ${ }^{15}$ which are not classified as illegal to use) other than cannabis was low in 2005, and less than in 2000 (see Table 3 ). The most commonly used drugs other than cannabis were ecstasy and cocaine, with four percent of male VDPs reporting ecstasy use at least once a month.

Overall, the proportion of all VDPs who reported being current users of any drug (including cannabis) was 17.9\% of males and $12.6 \%$ of females. There was a tendency for proportionally more males to report using these substances than females.

Table 4 shows the distribution of the reported number of drugs used by VDPs at any time (based on all eight substances) in 2000 and 2005. Among males, 12.5\% used $\geq 2$ drugs in 2005 compared to $19.2 \%$ in $2000(p=0.04)$. Among females, the corresponding estimates were $5.8 \%$ in 2005 and $10.6 \%$ in $2000(p=0.04)$. The proportion who were current users of $\geq 2$ drugs (ie cannabis at least once a week or other drugs at least once a month) was $4.5 \%$ (2005) and 7.4\% (2000) among males ( $p=0.16)$, and 2.5\% (2005) and 3.8\% (2000) among females $(p=0.40)$. These data indicate that illicit drug use has declined over the five-year period.

Table 3 shows that it was mainly users of cannabis who also report using other drugs because the proportion who used any drug is not much greater than the prevalence of cannabis use.

\section{Associations}

Reported illicit drug use was associated with alcohol drinking, and particularly with smoking (Table 5). A VDP who reported drinking but did not smoke was 8.5 times more likely to have used any illicit drug compared to someone who neither drank alcohol nor smoked; whereas someone who smoked but did not drink was 17.5 times more likely. However, a VDP who both drank and smoked was 39 times more likely to use drugs, though note should be made of the wide 95\% confidence interval.

\section{DISCUSSION}

This study, which had an identical design to one carried out five years before, provides information that can be used to obtain a trend in alcohol and drug use among VDPs. This approach can be used to conduct future studies. It reports on alcohol and drug use by VDPs before qualification and approximately five months into their VDP year. There may be some recall bias

\begin{tabular}{|c|c|c|c|c|}
\hline \multirow{2}{*}{$\begin{array}{l}\text { Number of } \\
\text { substances used }\end{array}$} & \multicolumn{2}{|l|}{ Males } & \multicolumn{2}{|l|}{ Females } \\
\hline & $\begin{array}{l}\% 2000 \\
(n=270)\end{array}$ & $\begin{array}{l}\% 2005 \\
(n=224)\end{array}$ & $\begin{array}{l}\% 2000 \\
(n=264)\end{array}$ & $\begin{array}{l}\% 2005 \\
(n=278)\end{array}$ \\
\hline 0 & 64.1 & 61.2 & 67.8 & 73.0 \\
\hline 1 & 16.7 & 26.3 & 21.6 & 21.2 \\
\hline 2 & 5.9 & 3.1 & 4.2 & 2.9 \\
\hline 3 & 1.8 & 3.6 & 2.6 & 1.4 \\
\hline 4 & 2.6 & 1.8 & 1.9 & 1.1 \\
\hline 5 & 3.3 & 2.7 & 1.1 & 0.4 \\
\hline 6 & 2.2 & 0.9 & 0.4 & 0 \\
\hline 7 & 3.0 & 0.4 & 0 & 0 \\
\hline 8 & 0.4 & 0 & 0.4 & 0 \\
\hline
\end{tabular}

\begin{tabular}{|c|c|c|c|c|}
\hline & $\begin{array}{l}\text { No alcohol } \\
\text { and never } \\
\text { smoked }\end{array}$ & $\begin{array}{l}\text { Smokes* } \\
\text { but does } \\
\text { not drink } \\
\text { alcohol }\end{array}$ & $\begin{array}{l}\text { Alcohol } \\
\text { drinker } \\
\text { but does } \\
\text { not smoke }\end{array}$ & $\begin{array}{l}\text { Both } \\
\text { smoker* } \\
\text { and drinker }\end{array}$ \\
\hline $\begin{array}{l}\text { Any drug used } \\
\text { at any time }\end{array}$ & $\begin{array}{l}1.4 \% \\
(1 / 70)\end{array}$ & $\begin{array}{l}25 \% \\
(6 / 24)\end{array}$ & $\begin{array}{l}12 \% \\
(20 / 164)\end{array}$ & $\begin{array}{l}55 \% \\
(135 / 244)\end{array}$ \\
\hline $\begin{array}{l}\text { Relative risk } \\
\text { of drug use } \\
(95 \% \mathrm{Cl})\end{array}$ & 1.0 & $\begin{array}{l}17.5 \\
(2.2-138)\end{array}$ & $\begin{array}{l}8.5 \\
(1.2-62)\end{array}$ & $\begin{array}{l}39 \\
(5.5-272)\end{array}$ \\
\hline
\end{tabular}

when reporting on information that occurred before the time as a VDP, as well as under-reporting of more highly stigmatised drugs. ${ }^{16}$ These factors should be taken into consideration when interpreting results of this study.

A response rate of $66 \%$ was achieved, below that seen in $2000(75 \%)$. This is acceptable but it is disappointing that all packs were not returned or administered by VDP advisors.

It would be inadvisable to compare the figures reported in this study with other studies on alcohol and drug use in society in general, or other subgroups, due to the lack of uniformity in methodologies and definitions of usage. However, trends can be compared between the general population and VDPs.

The reported use of tobacco by VDPs was less in 2005 than 2000, particularly among males. This downward trend, mirrored in the general population, ${ }^{6}$ is obviously encouraging. It will be interesting to see if this trend accelerates following the smoking ban in all enclosed public places in England and Wales in $2007^{17}$ and the earlier ban in Scotland.

Figures quoted for sensible weekly alcohol consumption levels (0-21 units for men, 0-14 units for women) are those recommended by the British Medical Association ${ }^{18}$ as in the 2000 study. The reason for this is the continued lack of medical justification of those levels recommended by the Department of Health $^{19}$ (up to 21 units for females, up to 28 units for males). Alcohol consumption by VDPs is still high. The proportion who binge drink is about 40\%, with little change between 2000 and 
2005. While drinking associated with 'increased' or 'hazardous risk' to health in males has not changed much, there was a significant reduction among females. With the 'pub crawl' being re-branded a 'cultural leisure activity' ${ }^{20}$ and young women an increasing target of alcohol marketing, only time will tell if this trend, also found in the general population, ${ }^{8}$ will continue.

VDPs alcohol consumption reported 'last week' tends to be higher than that reported during an 'average week'. This is consistent with the findings from the 2000 study and would suggest that VDPs underestimate the actual amount of alcohol they consume. This has implications as to how undergraduates and VDPs should be educated about safe drinking limits, with the possible use of an alcohol diary being of benefit. ${ }^{21}$

Cannabis is still the most popular illicit drug used by VDPs in 2005 , as it was in 2000 , though the proportion of users was somewhat lower in 2005 but this was not statistically significant. Whether the reclassification of cannabis from a class $\mathrm{B}$ to a class $\mathrm{C}$ drug will alter this trend may be revealed in future repeats of this study. Although the prevalence of illicit drug use seems to be decreasing over time, male VDPs continue to use more drugs than female VDPs. A strong association between illicit drug use and those reporting tobacco and alcohol use was found. This may suggest that targeted advice could be given to those who use tobacco and alcohol on harm reduction methods when using illicit drugs.

The results of this study do not show if VDPs reporting smoking tobacco, drinking alcohol above sensible limits, binge drinking or using illicit drugs has had a detrimental effect on the quality of care they give their patients. However, continuation of these activities after VT is likely to have negative effects on personal health and may result in criminal prosecution with obvious repercussions for professional status.

A recent study carried out in the USA found that "contrary to previous speculation, there is little evidence from the prevalence data the authors analyzed for this report to suggest that dentists are at a greater risk of developing alcohol or other drug-use problems than is the general population'.22 Also, a study carried out in 2001 comparing tobacco, alcohol and drug use among dental and law undergraduates ${ }^{23}$ found law students smoked more and used cannabis more frequently, with all other substances being used at a similar levels. Whether this pattern continues post-qualification is not known, but it would tend to suggest the dental profession is not exceptional in its members' use of alcohol and illicit drugs.

It is appropriate that education about smoking, alcohol and illicit drugs is incorporated in a wider personal, health and social education programme, which should start in the first year as a dental undergraduate and be updated throughout a dentist's professional career. The programme should include harm minimisation as well as primary prevention and take account of culture and belief. Such programmes need to be sustained, evaluated and evidence-based. ${ }^{24}$

\section{CONCLUSION}

This study has found the level of alcohol, tobacco and illicit drug use (excluding cannabis) among VDPs decreasing since 2000 , but levels of binge drinking and cannabis use remaining similar.

The authors would like to acknowledge Mr Paul Cook (Postgraduate Dental Dean, Yorkshire) and The Yorkshire Deanery, whose support made this study possible.

1. NHS Dental Vocational Training in England. Aims and Objectives. http://www. copdend.org.uk/dvt (accessed 10 November 2007).

2. Underwood B, Fox K, Nixon P J. Alcohol and drug use among vocational dental practitioners. Br Dent J 2003; 195: 265-268.

3. General Dental Council. Standards for dental professionals. London: General Dental Council, 2005.

4. General Dental Council. Maintaining standards. London: General Dental Council, 1997.

5. Paddick J. Policy \&t Development Officer, General Dental Council. Email correspondence, 2005

6. Office for National Statistics. Cigarette smoking. Slight fall in smoking prevalence. National Statistics Online, 28 November 2006. http://www.statistics.gov. uk/cci/nugget.asp?id=866 (accessed 14 March 2007).

7. The Information Centre. Statistics on alcohol: England, 2006. Leeds: The Information Centre, 2006. http://www.ic.nhs.uk/statistics-and-data-collections/ health-and-lifestyles/alcohol/statistics-on-alcohol:-england-2006 (accessed 1 November 2007).

8. Office for National Statistics. Drinking. Fewer men exceeding benchmarks. National Statistics Online, 28 November 2006. http://www.statistics.gov.uk/cci/ nugget.asp?id=1027 (accessed 14 March 2007).

9. Wright J D, Pearl L. Experience and knowledge of young people regarding illicit drug use, 1969-99. Addiction 2000; 95: 1225-1235.

10. Balding J. Young people and illegal drugs into 2000. Exeter: Schools Health Education Unit, 2000

11. The Information Centre. Statistics on young people and drug misuse: England 2006. Leeds: The Information Centre, 2006. http://www.ic.nhs.uk/pubs/youngpeopledrugmisuse2006 (accessed 14 March 2007).

12. Parker $\mathrm{H}$, Aldridge J, Measham F. Illegal leisure: the normalisation of adolescent recreational drug use. London: Routledge, 1998.

13. Alcohol Concern. Fact sheet 20. Binge drinking. London: Alcohol Concern, 2003.

14. Frank. A-Z of drugs - poppers. http://www.talktofrank.com/drugs.aspx?id=198 (accessed 1 November 2007).

15. Frank. A-Z of drugs - gases, glues and aerosols. http://www.talktofrank.com/ drugs.aspx?id=182 (accessed 1 November 2007).

16. National Institute on Drug Abuse. The validity of self-reported drug use: improving the accuracy of survey estimates. NIDA Research Monograph 167. pp 247272. Washington: U.S Department of Health and Human Services, 1997.

17. Department of Health. New health bill will deliver commitment to ban smoking in majority of workplaces. Press release, 27 October 2005. http://www.dh.gov.uk/en/ Publicationsandstatistics/Pressreleases/DH_4122137 (accessed 1 November 2007).

18. British Medical Association. Alcohol: guidelines on sensible drinking. London: BMA, 1995.

19. Department of Health. Sensible drinking. The report of an inter-departmental working group. London: Department of Health, 1995.

20. Hall S. Booze nation. Druglink 2005; 20(6): 18-19.

21. Cancer Research UK website. News and resources: alcohol. http://info.cancerresearchuk.org/healthyliving/alcohol/ (accessed 30 September 2006).

22. Kenna G A, Wood M D. The prevalence of alcohol, cigarette and illicit drug use and problems among dentists. J Am Dent Assoc 2005; 136: 1023-1032; erratum 1224.

23. Barber $\mathrm{M} \mathrm{W}$, Fairclough A. A comparison of alcohol and drug use among dental undergraduates and a group of non-medical, professional undergraduates. BrDent J 2006; 201: 581-584.

24. Coggans N. Thirty years of drug education: whose learning curve? DrugLink 1998; 13(6): 12-14 